\title{
ÉPOCA DE COLETA E ÁCIDO INDOLBUTÍRICO NO ENRAIZAMENTO DE ESTACAS DE ESPIRRADEIRA (Nerium oleander L.) ${ }^{1}$
}

\author{
Kathia Fernandes Lopes Pivetta ${ }^{2}$, Denise Renata Pedrinho ${ }^{3}$, Silvio Fávero ${ }^{3}$, Gisele Sales Batista ${ }^{4}$ e Renata \\ Bachin Mazzini ${ }^{4}$
}

\begin{abstract}
RESUMO - A espirradeira (Nerium oleander L.) é uma importante espécie arbórea ornamental, muito utilizada no meio urbano. É propagada por estacas, porém a porcentagem de enraizamento é baixa e não há estudos sobre fatores que influenciam nesse processo. Este trabalho teve, portanto, o objetivo de estudar o efeito da época de coleta e do ácido indolbutírico (AIB) no enraizamento de estacas de duas variedades de espirradeira (Nerium oleander L.), determinadas pela coloração das flores (rosa e branca). O experimento foi instalado na UNESP, Campus de Jaboticabal/SP, no verão e no inverno. O delineamento experimental foi em blocos casualizados em esquema fatorial 2 × 2 x 4 (duas variedades combinadas com duas estações do ano e quatro concentrações de AIB - 0, 1.000, 2.000 e $4.000 \mathrm{mg} \mathrm{kg}^{-1}$ ). As avaliações foram realizadas 60 dias após a estaquia, sendo estas as variáveis: porcentagem de enraizamento, número médio, comprimento e massa de matéria seca de raízes. Concluiu-se que o enraizamento de ambas as variedades de espirradeira (rosa e branca) foi superior no verão. A variedade de flores rosas apresentou maior número e comprimento médio de raízes no verão, porém as maiores porcentagens de enraizamento e massa de matéria seca de raízes foram encontradas no inverno. O ácido indolbutírico foi efetivo para aumentar a porcentagem de enraizamento nas concentrações testadas de 1.000 e $2.000 \mathrm{mg} \mathrm{kg}^{-1}$; maior número, comprimento e massa de matéria seca de raízes foram obtidos na concentração de $2.000 \mathrm{mg} \mathrm{kg}^{-1}$.
\end{abstract}

Palavras-chave: Estaquia, AIB e Propagação assexuada.

\section{HARVESTING TIME AND INDOLEBUTYRIC ACID ON THE ROOTING OF Nerium oleander L. CUTTINGS}

\begin{abstract}
Nerium oleander plants are important ornamental trees, much cultivated in urban centers. This species is propagated by cuttings, but rooting percentage is very low and there are no studies on the factors that influence this process. Therefore, the objective of this work was to study the effect of the harvesting time and the indolebutyric acid (IBA) on the rooting of cuttings of two Nerium oleander varieties, determined by flower color (pink and white). The experiments were conducted at UNESP, Campus of Jaboticabal, São Paulo State, Brazil, during summer and winter. The experimental design was in randomized blocks and the treatments were organized in a $2 \times 2 \times 4$ factorial arrangement (two varieties, two harvesting times and four IBA concentrations - 0, 1000, 2000 and $4000 \mathrm{mg} \mathrm{kg}^{-1}$ ). The evaluations were done 60 days after the cuttings, and the following variables were observed: percentage of rooting, mean root number, mean root length and mean root dry mass. Rooting of the two varieties was higher in summer (97\%) when compared to winter (77\% and 56\% respectively for the pink variety showed higher rooting percentage and root dry mass in winter and higher number and length of roots in summer; the indolebutyric acid concentrations of 1000 and $2000 \mathrm{mg} \mathrm{kg}^{-1} \mathrm{increased}$ the rooting percentage, and the $2000 \mathrm{mg} \mathrm{kg}^{-1}$ one increased root number, root length and root dry mass.
\end{abstract}

Keywords: Cuttings, IBA and Asexual propagation

\footnotetext{
${ }^{1}$ Recebido em 12.05.2010 e aceito para publicação em 15.11.2011.

${ }^{2}$ Universidade Estadual Paulista Júlio de Mesquita Filho, UNESP, Jaboticabal/SP, Brasil. E-mail: <kathia@fcav.unesp.br>. ${ }^{3}$ Universidade Anhanguera Uniderp, UNIDERP, Campo Grande/MS, Brasil. E-mail: <dpedrinho@hotmail.com>e <silvio.favero@aesapar.com>.

${ }^{4}$ Programa de Pós-Graduação em Agronomia (Produção Vegetal), Universidade Estadual Paulista Júlio de Mesquita Filho, UNESP, Jaboticabal/SP, Brasil.E-mail: <gismel@gmail.com> e < remazzini@yahoo.com.br>.
} 


\section{INTRODUÇÃO}

A espécie Nerium oleander L., comumente chamada de espirradeira ou oleandro, é originária do Mediterrâneo e pertence à Família Apocynaceae. Apresenta de 3 a $5 \mathrm{~m}$ de altura, é lactescente, muito ramificada e florífera, de folhas persistentes e coriáceas. As flores são brancas, róseas ou vermelhas e formam-se na primavera e no verão. Há diversas variedades que se diferenciam pelo colorido das flores, as quais podem ser simples ou dobradas, bem como das folhas, podendo ser inteiramente verdes ou variegadas. É muito cultivada em parques, jardins e arborização de ruas, inclusive em regiões de clima frio e mesmo áridas (LORENZI; SOUZA, 2001).

As auxinas desempenham papel importante, estando o efeito principal sobre o enraizamento de estacas ligado à sua ação sobre a indução de primórdios radiculares. A aplicação exógena de auxina também proporciona maior porcentagem, velocidade, qualidade e uniformidade de enraizamento de estacas (HARTMANN et al., 2002; FACHINELLO et al., 2005).

Muitos estudos têm sido realizados a fim de traçar a curva de resposta de diferentes espécies, cultivares e tipos de estaca nas diferentes concentrações de auxina, entre eles Martins (1998), Pivetta et al. (1999), Nicoloso et al. (1999), Pivetta et al. (2001), Ramos et al. (2003), Pedrinho et al. (2003), Sarzi e Pivetta (2005), Carvalho et al. (2005), Almeida et al. (2007), Valmorbida et al. (2008), Gratieri-Sossella et al. (2008), Oliveira et al. (2009) e Souza et al. (2009).

A época de coleta das estacas influencia o enraizamento das espécies, sendo a primavera e o verão as estações que proporcionam maior capacidade às plantas de enraizar; porém, a coleta pode ser realizada em qualquer época do ano, dependendo apenas da disponibilidade e necessidade de material (MARTINS, 1998).

Embora a espirradeira seja propagada por estacas, a porcentagem de enraizamento é baixa, e não há estudos sobre fatores que influenciam nesse processo. Nesse contexto, este trabalho objetivou estudar o efeito da época de coleta e do ácido indolbutírico (AIB) no enraizamento de estacas de duas variedades de Nerium oleander L., determinadas pela coloração das flores (rosa e branca).

Revista Árvore, Viçosa-MG, v.36, n.1, p.17-23, 2012

\footnotetext{
Revista Ârvore, Viçosa-MG, v.36, n.1, p.17-23, 2012
}

\section{MATERIAL E MÉTODOS}

As estacas foram coletadas de duas variedades de espirradeira, definidas pela coloração das flores (rosa e branca), no Município de Jaboticabal, SP.

Os tratamentos utilizados foram duas épocas de coleta das estacas (verão e inverno), quatro concentrações de AIB (0, 1.000, 2.000 e $\left.4.000 \mathrm{mg} \mathrm{kg}^{-1}\right)$ e duas variedades de espirradeira determinadas pela coloração das flores (rosa e branca).

O delineamento experimental foi em blocos casualizados, em esquema fatorial $2 \times 2 \times 4$ (duas variedades de espirradeira combinadas com duas épocas de coleta - verão e inverno e quatro concentrações de AIB - 0, 1.000, 2.000 e $4.000 \mathrm{mg} \mathrm{kg}^{-1}$ ), sendo 16 tratamentos e quatro repetições, num total de 64 parcelas, sendo cinco estacas por parcela.

Estacas herbáceas foram cortadas com aproximadamente $15 \mathrm{~cm}$ de comprimento, mantendo-se um par de folhas e duas gemas. Após o preparo, as bases das estacas foram tratadas com AIB, nas diferentes concentrações, de acordo com o tratamento, via pó, utilizando-se como veículo o talco industrial. O estaqueamento foi feito em bandejas de poliestireno com 72 células, preenchidas com vermiculita de granulometria média. As bandejas foram mantidas em câmara de nebulização intermitente do Viveiro Experimental de Plantas Ornamentais e Florestais da FCAV/UNESP, no Município de Jaboticabal, SP.

A avaliação foi realizada 60 dias após a estaquia, anotando-se o número de estacas enraizadas (calculando-se, posteriormente, a porcentagem de enraizamento), número, comprimento médio e massa de matéria seca de raízes por estaca.

Como critério adotado no experimento para a contagem de raízes, toda estaca que apresentava pelo menos uma raiz adventícia com comprimento igual ou superior a $2 \mathrm{~mm}$ foi considerada enraizada, e essas raízes foram anotadas e medidas com régua milimetrada, calculando-se a média por estaca.

Para a avaliação da massa de matéria seca das raízes, o material foi submetido à secagem em estufa de circulação de ar forçada, a $70{ }^{\circ} \mathrm{C}$, até que permanecesse em massa constante, utilizando-se, para a pesagem, balança digital de precisão (quatro dígitos decimais). 
Para as análises estatísticas, os dados de porcentagem de enraizamento e número médio de raízes foram transformados em arco-seno $\sqrt{x / 100}$ e $\sqrt{x+0,50}$, respectivamente. Os dados de comprimento médio de raízes e de massa de matéria seca de raízes não foram transformados.

Os dados coletados, transformados quando necessários, foram submetidos à análise de variância. Para o estudo dos efeitos da época e da variedade, as médias foram comparadas pelo teste de Tukey a $5 \%$ de probabilidade, enquanto no estudo do efeito do AIB foi realizada a regressão polinomial, a fim de verificar a resposta das variáveis em função do aumento da concentração de AIB.

\section{RESULTADOS}

As características radiculares mensuradas variaram entre variedades no verão e no inverno. A variedade branca ora apresentava valores significativamente menores, ora valores significativamente semelhantes à variedade rosa para as diferentes características radiculares. A porcentagem de enraizamento foi significativamente superior no verão, e ambas as variedades apresentaram $97 \%$ de enraizamento. No inverno houve diferença significativa entre as duas variedades, e a de flores rosas apresentou valor significativamente maior de porcentagem de enraizamento que a de flores brancas, ou seja, 77 e $56 \%$, respectivamente (Tabela 1 ).

Relacionada à aplicação de AIB, houve diferença entre as concentrações, observando-se ajuste de regressão quadrática (Figura 1A), em que maiores porcentagens de enraizamento, das concentrações testadas, foram verificadas nas estacas tratadas com 1.000 e $2.000 \mathrm{mg} \mathrm{kg}^{-1}$, respectivamente, 88,29 e 87,91\%. A média máxima foi estimada na concentração de $1.332,99 \mathrm{mg} \mathrm{kg}^{-1}$, correspondendo a $88,41 \%$.

O número de raízes por estaca também foi significativamente superior no verão, em ambas as variedades. As estacas de espirradeira de flores rosas

Tabela 1 - Médias obtidas das análises de variância da porcentagem de enraizamento, número de raízes, comprimento de raízes $(\mathrm{cm})$ e massa de matéria seca de raízes (mg) de raízes em estacas de espirradeira (Nerium oleander L.), de flores brancas e rosas, retiradas no verão e no inverno. Jaboticabal, SP, 2010.

Table 1 - Mean rooting percentage, root number, root length $(\mathrm{cm})$ and root dry mass $(\mathrm{mg})$ from the variance analysis for cuttings of two varieties of Nerium oleander, with pink or white flowers, harvested in summer and winter time. Jaboticabal, São Paulo State, Brazil, 2010.

\begin{tabular}{|c|c|c|}
\hline & \multicolumn{2}{|c|}{ Porcentagem de enraizamento $^{1}$} \\
\hline & Branca & Rosa \\
\hline \multirow{4}{*}{$\begin{array}{c}\text { Verão } \\
\text { Inverno }\end{array}$} & $80,73^{1}(97,41)^{3} \mathrm{aA}$ & $80,39(97,21)$ aA \\
\hline & $48,22 \quad(55,61) \quad$ bB & $61,65(77,45)$ bA \\
\hline & \multicolumn{2}{|c|}{ Número médio de raízes ${ }^{2}$} \\
\hline & Branca & Rosa \\
\hline \multirow{4}{*}{$\begin{array}{c}\text { Verão } \\
\text { Inverno }\end{array}$} & $4,08^{1}(16,15)$ aB & $4,35(18,42)$ aA \\
\hline & $3,47 \quad(11,54) \quad$ bA & $3,42(11,20)$ bA \\
\hline & \multicolumn{2}{|c|}{ Comprimento médio de raízes $(\mathrm{cm})$} \\
\hline & Branca & Rosa \\
\hline Verão & $3,51 \mathrm{aB}$ & $4,67 \mathrm{aA}$ \\
\hline \multirow[t]{3}{*}{ Inverno } & $2,89 \mathrm{bA}$ & $3,26 \mathrm{bA}$ \\
\hline & \multicolumn{2}{|c|}{ Massa de matéria seca de raízes (mg) } \\
\hline & Branca & Rosa \\
\hline Verão & 26,71 aA & 26,83 aA \\
\hline Inverno & $22,54 \mathrm{bB}$ & 26,53 aA \\
\hline \multicolumn{3}{|c|}{ Dados transformados em arco-seno $\sqrt{x / 100}$. } \\
\hline \multirow{2}{*}{\multicolumn{3}{|c|}{$\begin{array}{l}2 \text { Dados transformados em } \sqrt{x+0,50} \text {. } \\
{ }^{3} \text { Dados não transformados. }\end{array}$}} \\
\hline & & \\
\hline \multicolumn{3}{|c|}{$\begin{array}{l}\text { NS: Não significativo }(\mathrm{P}>0,05) \text {; } \text { significativo }(\mathrm{P}<0,05) \text {; e } * * \text { significativo }(\mathrm{P}<0,01) \text {. } \\
\text { Médias seguidas da mesma letra maiúscula na linha e minúscula na coluna não diferem entre si, pelo teste de Tukey a } 5 \% \\
\text { de probabilidade. }\end{array}$} \\
\hline
\end{tabular}

Revista Árvore, Viçosa-MG, v.36, n.1, p.17-23, 2012 
tiveram número de raízes significativamente superior quando comparadas com as de flores brancas somente no verão (Tabela 1 ).

Observou-se ajuste de regressão quadrática (Figura 1B), em que o número de raízes é crescente até a concentração testada de $2.000 \mathrm{mg} \mathrm{kg}^{-1}$, correspondendo a 15,8 raízes/ muda formada, decrescendo a partir desse ponto. A média máxima estimada foi obtida na concentração de $1.870,37 \mathrm{mg} \mathrm{kg}^{-1}$, correspondendo também a 15,8 raízes/muda.

Analisando o comprimento médio de raízes, observou-se que os valores obtidos no verão foram significativamente superiores aos obtidos no inverno e que o comprimento médio das raízes da variedade de flores rosas foi significativamente superior quando comparado com as de flores brancas somente no verão (Tabela 1).

Em relação às concentrações de AIB, houve ajuste de regressão quadrática (Figura 1C), em que se observou maior média estimada na concentração de $2.238,10 \mathrm{mg} \mathrm{kg}^{-1}$, correspondendo a $4,08 \mathrm{~cm}$. Entre as concentrações testadas, a de $2.000 \mathrm{mgkg}^{-1}$ foi a que proporcionou maior comprimento médio de raízes, correspondendo a $4,07 \mathrm{~cm}$.

Para massa de matéria seca de raízes (Tabela 1), observou-se que a superioridade do verão foi verificada somente na variedade de flores brancas; nas de flores
(A)

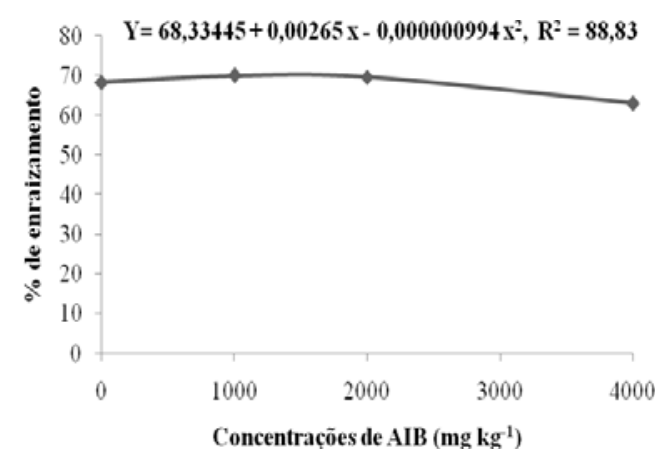

(C)

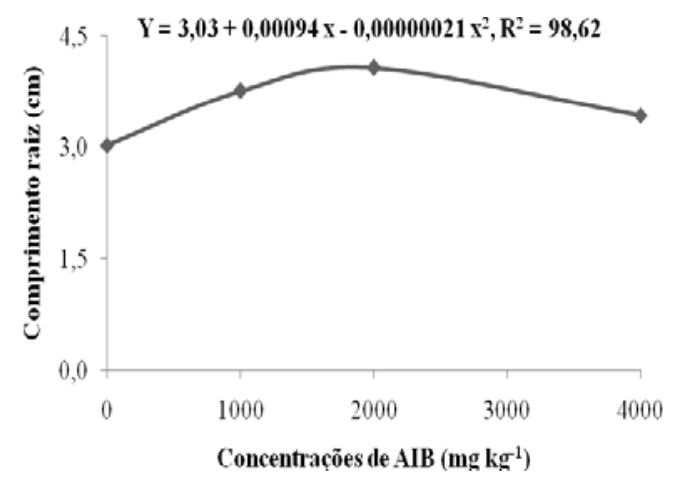

(B)

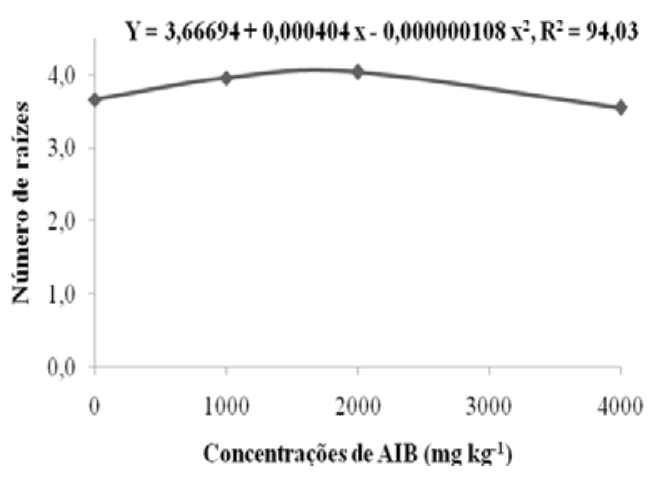

(D)

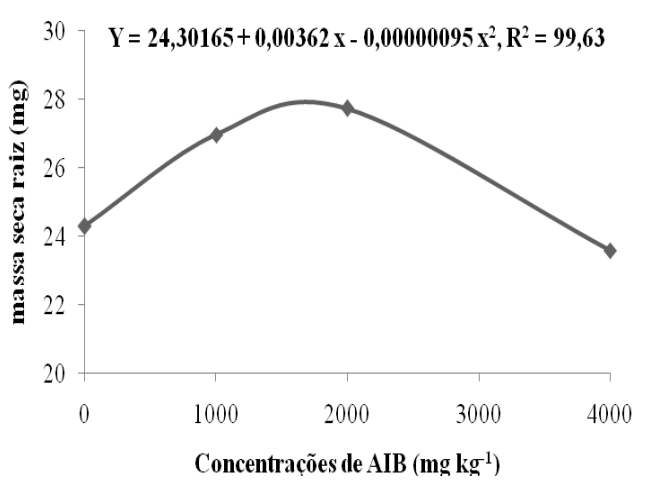

Figura 1 - Curva de regressão entre as concentrações de AIB (mg kg-1): porcentagem de enraizamento - dados transformados em arco-seno $\sqrt{x / 100}$ (A); número de raízes - dados transformados em $\sqrt{x+0,50}$ (B); comprimento médio de raiz (cm) (C); e massa de matéria seca de raízes (mg) (D) de estacas de espirradeira (Nerium oleander L.) de flores rosas e brancas no verão e no inverno. Jaboticabal, SP, 2010.

Figure 1 - Regression analysis amongst the IBA concentrations (mg kg-1): rooting percentage - data transformed to arc sen $\sqrt{x / 100}$ (A); root number - data transformed to $\sqrt{x+0,50}$ (B); mean root length $(\mathrm{cm})(\mathrm{C})$ and root dry mass $(\mathrm{mg})(\mathrm{D})$ for cuttings of two varieties of Nerium oleander L., with pink or white flowers, harvested in summer and winter time. Jaboticabal city, São Paulo State, Brazil, 2010.

Revista Árvore, Viçosa-MG, v.36, n.1, p.17-23, 2012 
rosas, não houve diferença entre as duas estações. A variedade de flores rosas foi significativamente superior à de flores brancas no inverno.

Houve ajuste de regressão quadrática (Figura 1D) nas concentrações de AIB, sendo a maior média estimada na concentração de $1.905,26 \mathrm{mg} \mathrm{kg}^{-1}$, correspondendo a $27,75 \mathrm{mg}$. A concentração de $2.000 \mathrm{mg} \mathrm{kg}^{-1}$ apresentou maior média de massa de matéria seca de raízes, em comparação com as demais testadas, correspondendo a 27,74 mg.

\section{DISCUSSÃO}

A superioridade do verão pode ter sido em virtude de ser um período de intenso crescimento vegetativo, em que as estacas estão mais herbáceas, facilitando, de modo geral, o desenvolvimento de raízes em espécies com dificuldade de enraizamento, conforme preconizaram Fachinello et al. (2005). No inverno, a taxa fotossintética é baixa, em consequência da baixa luminosidade e temperatura ambiente. Assim, os metabólicos da fotossíntese são reduzidos, sendo insuficientes para a iniciação e desenvolvimento das raízes (ONO e RODRIGUES, 1996). Maiores porcentagens de enraizamento obtidas no verão e, ou, na primavera, em detrimento do inverno e, ou, do outono, também foram observadas em outras espécies, como catiguá, Trichilia catigua (VALMORBIDA et al., 2008), lichieira, Litchi chinensis (CARVALHO et al., 2005) e minirrosa, Rosa spp. (SARZI; PIVETTA, 2005).

Alguns estudos, como os realizados por Sarzi e Chalfun (1989), Corrêa (2001) e Pivetta (2005), têm mostrado que as variedades com flores coloridas têm apresentado maior porcentagem de enraizamento, ou enraizamento mais rápido, em comparação com as de flores brancas, como mostrado neste estudo na época de inverno. No entanto, as bases fisiológicas dessa diferença de resposta ainda não foram elucidadas.

Neste estudo, observou-se que, embora a maior média de porcentagem de enraizamento tenha sido estimada na concentração de $1.333 \mathrm{mg} \mathrm{kg}^{-1}$ de AIB, o valor foi semelhante aos obtidos nas concentrações de 1.000 e $2.000 \mathrm{mg} \mathrm{kg}^{-1}$, ou seja, 88,41\%, 88,29\% e 87,91\%, respectivamente, para 1.333, 1.000 e $2.000 \mathrm{mg} \mathrm{kg}^{-1}$.

De forma semelhante, a concentração de $1.000 \mathrm{mg} \mathrm{L}^{-1}$ também favoreceu o enraizamento de estacas herbáceas provenientes de plantas jovens de Erythrina crista- galli (GRATIERI-SOSSELLA et al., 2008) e de estacas herbáceas de minirroseiras de flores de coloração rosa (SARZI; PIVETTA, 2005). Pivetta et al. (1999), estudando o enraizamento de estacas de roseira 'Red Success', também observaram resultados semelhantes ao deste estudo, em que a maior porcentagem de enraizamento 15 dias após a estaquia, para estacas apicais e medianas, foi próxima de $1.000 \mathrm{mg} \mathrm{L}^{-1}$ e para estacas basais, $2.000 \mathrm{mg} \mathrm{L}^{-1}$. Martins (1998) também obteve curva semelhante quando tratou estacas de lichieira 'Bengal' com AIB.

Observou-se ainda, neste estudo, que os valores máximos estimados para número, comprimento médio e massa de matéria seca de raízes foram muito semelhantes aos obtidos na concentração de $2.000 \mathrm{mg} \mathrm{kg}^{-1}$, que entre as testadas foi a que resultou em maiores médias para essas características.

Vários autores também verificaram aumento no número e comprimento médio de raízes com a utilização de AIB, em diferentes espécies, semelhante ao observado neste estudo, entre eles Martins (1998), Pivetta et al. (1999), Pivetta et al. (2001) e Carvalho et al. (2005). No entanto, Nicoloso et al. (1999) e Souza et al. (2009) não observaram o efeito positivo da utilização do AIB no comprimento médio de raízes de mudas de Platanus acerifolia e Toona ciliata, respectivamente.

Já neste estudo foi observado o efeito positivo do AIB no enraizamento das estacas de espirradeira, como preconizado por Hartmann et al. (2002) e Fachinello et al. (2005) e verificado por alguns autores que trabalharam com outras plantas, sendo a concentração ótima variável com a espécie (HARTMANN et al., 2002). Também foi observada resposta quadrática ao aumento da concentração de AIB para todas as variáveis, indicando que a concentração de $4.000 \mathrm{mg} \cdot \mathrm{kg}^{-1}$ apresentou efeito inibitório ou fitotóxico, conforme preconizaram Hartmann et al. (2002).

\section{CONCLUSÃO}

O enraizamento de ambas as variedades (rosa e branca) de Nerium oleander L. foi superior no verão. A variedade de flores rosas apresentou maior porcentagem de enraizamento e massa de matéria seca de raízes no inverno e maior número e comprimento médio de raízes no verão, em comparação com as de flores brancas. O ácido indolbutírico foi

Revista Árvore, Viçosa-MG, v.36, n.1, p.17-23, 2012 
efetivo para aumentar a porcentagem de enraizamento nas concentrações testadas de 1.000 e $2.000 \mathrm{mg} \mathrm{kg}^{-1}$; já maior número, comprimento e massa de matéria seca de raízes foram obtidos na concentração de $2.000 \mathrm{mg} \mathrm{kg}^{-1}$.

\section{REFERÊNCIAS}

ALMEIDA, F. D. et al. Eficiência das auxinas (AIB e ANA) no enraizamento de miniestacas de clones de Eucalyptus cloeziana F. Muell. Revista Árvore, v.31, n.3, p.455-463, 2007.

CARVALHO, C. M.; CUNHA, R. J. P.; RODRIGUES, J. D. Enraizamento de estacas semilenhosas de lichieira utilizando ácido indolbutírico. Revista Brasileira de Fruticultura, v.27, n.1, p.95-97, 2005.

CHALFUn, N. N. J. Fatores bioquímicos e fisiológicos no enraizamento de estacas de Hibiscus rosa-sinensis L. 1989. $85 \mathrm{f}$. Tese (Doutorado em Fitotecnia) - Universidade Federal de Viçosa, Viçosa, 1989.

CORRÊA, C. D. S. Efeito do tipo de estaca, do ácido indolbutírico e do boro no enraizamento de estacas de azaléia (Rhododendron simsii Planch.). 2001. 61f. Monografia (Trabalho de Graduação em Agronomia) - Faculdade de Ciências Agronômicas, Universidade Estadual Paulista, Jaboticabal, 2001.

FACHINELLO, J. C. et al. Propagação vegetativa por estaquia. In: FACHINELLO, J. C.; HOFFMANN, A.; NACHTIGAL, J. C. (Eds.) Propagação de plantas frutíferas de clima temperado. Brasília: Embrapa Informação Tecnológica, 2005. p.69-71.

GRATIERI-SOSSELLA, A.; PETRY, C.; NIENOW, A. A. Propagação da corticeira do banhado (Erythrina crista-galli L.) (Fabaceae) pelo processo de estaquia. Revista Árvore, v.32, n.1, p.163-171, 2008.

HARTMANN, H. T. et al. Plant propagation: principles and practices. 7.ed. New Jersey: Prentice-Hall, 2002. 880p.

Revista Árvore, Viçosa-MG, v.36, n.1, p.17-23, 2012
LORENZI, H.; SOUZA, H. M. Plantas ornamentais no Brasil: arbustivas, herbáceas e trepadeiras. 3.ed. Nova Odessa: Instituto Plantarum, 2001. 1088p.

MARTINS, A. B. G. Enraizamento de estacas enfolhadas de três variedades de lichia (Litchi chinensis Sonn.). 1998. 100f. Tese (Doutorado em Agronomia) - Faculdade de Ciências Agronômicas, Universidade Estadual Paulista, Jaboticabal, 1998.

NICOLOSO, F. T.; LAZZARI, M.; FORTUNATO, R. P. Propagação vegetativa de Platanus acerifolia Ait: (II) Efeito da aplicação de zinco, boro e ácido indolbutírico no enraizamento de estacas.

Ciência Rural, v.29, n.3, p.487-492, 1999.

OLIVEIRA, A. F. et al. Estaquia de oliveira em diferentes épocas, substratos e doses de AIB diluído em $\mathrm{NaOH}$ e álcool. Ciência e Agrotecnologia, v.33, n.1, p.79-85, 2009.

ONO, E.; RODRIGUES, J. D. Aspectos da fisiologia do enraizamento de estacas caulinares. Jaboticabal: FUNEP, 1996. 83p.

PEDRINHO, D. R. et al. Efeito do armazenamento de estacas no enraizamento de roseiras para corte nas quatro estações do ano. Revista

Brasileira de Horticultura

Ornamental, v.9, n.1, p.25-30, 2003.

PIVETTA, K. F. L. et al. Efeito do tipo de fornecimento e de concentrações do ácido indolbutírico no enraizamento de estacas enfolhadas de roseira (Rosa sp.) 'Red Success'. Científica, v.29, n.1/2, p.33-43, 2001.

PIVETTA, K. F. L. et al. Effect of type of cuttings and indolbutyric acid on the rooting of rose (Rosa sp.

'Red Success') leafy cuttings during two seasons.

Acta Horticulturae, n.482, p.333-338, 1999.

RAMOS, J. D. et al. Enraizamento de estacas herbáceas de ‘Mirabolano’ (Prunus cerasifera Ehrn.) em diferentes substratos e concentrações de ácido indolbutírico. Revista Brasileira de Fruticultura, v.25, n.1, p.189-191, 2003.

SARZI, I.; PIVETTA, K. F. L. Efeito das estações do ano e do ácido indolbutírico no enraizamento de estacas de variedades de mini-roseira (Rosa spp.). Científica, v.33, n.1, p.62-68, 2005. 
SOUZA, J. C. A. V. et al. Propagação vegetativa de cedro-australiano (Toona ciliata M. Roemer) por miniestaquia. Revista Árvore, v.33, n.2, p.205-213, 2009.
VALMORBIDA, J. et al. Enraizamento de estacas de Trichilia catigua A. Jus(Catiguá) em diferentes estações do ano. Revista Árvore, v.32, n.3, p.435-442, 2008. 